\title{
Detection of Haemophilus influenzae in cerebrospinal fluids by polymerase chain reaction DNA amplification
}

\author{
R. J. VAN KETEL, B. DE WEVER and L. VAN ALPHEN* \\ Department of Medical Microbiology, Academic Medical Center, Meibergdreef 9, 1105 AZ Amsterdam and \\ "Department of Microbiology and Netherlands Reference Laboratory for Bacterial Meningitis, University of \\ Amsterdam, The Netherlands
}

Summary. Two primer sets were chosen for the detection of Haemophilus influenzae in
cerebrospinal fluid by polymerase chain reaction (PCR) DNA amplification. One
primer set was selected from sequences encoding a capsulation-associated protein
and reacted with target DNA from all 15 capsulate $H$. influenzae strains (all serotypes)
examined. The other primer set was selected from the DNA sequence of a gene
encoding for outer-membrane protein P6 and reacted with the 15 capsulate and 10
non-capsulate strains of $H$. influenzae tested. This primer set also reacted with the
closely related species $H$. haemolyticus and $H$. aegyptius, and with two of nine $H$.
parainfluenzae strains. In reconstruction experiments, PCR DNA amplification was
able to detect as few as five $H$. influenzae cells when 40 cycles of amplification were
used. Two hundred cerebrospinal fluid (CSF) samples collected consecutively from
patients suffering from meningitis were investigated by PCR; 40 were culture-positive
for $H$. influenzae and 39 of these were also clearly positive in the PCR test with both
primer sets. Contamination occurred to some extent with 40 cycles of amplification
but was completely eliminated when the number of cycles was reduced to 35 . We
conclude that the two primer sets are appropriate for the detection of $H$. influenzae by
PCR, each having its own specificity. When these two primer sets are used, PCR is a
technique of equivalent sensitivity to culture for the detection of $H$. influenzae in CSF.

\section{Introduction}

In-vitro DNA amplification by the polymerase chain reaction (PCR $)^{1}$ is a new technology that has considerable implications for diagnostic microbiology because of its potentially exquisite specificity and sensitivity. Besides its application in the prenatal diagnosis of genetic defects, published reports on the adaptation of PCR to the diagnosis of infectious diseases have focused initially on the detection of viral agents. ${ }^{2-4}$ More recently, PCR assays have been reported for the detection of Legionella pneumophila, ${ }^{5}$ leptospires, ${ }^{6}$ Mycobacterium tuberculosis ${ }^{7}$ and parasites such as Toxoplasma gondii ${ }^{8}$ and others. The pronounced sensitivity to contamination is a distinct drawback of PCR assays. ${ }^{9}$

Comparison of the sensitivity and specificity of PCR assays with well established microbial detection techniques is needed to determine the clinical usefulness of the new technology. For the diagnosis of Haemophilus influenzae meningitis, culture is well established and easily performed. Additional

Received 29 March 1990; accepted 5 June 1990. information, i.e., the clinical presentation, the properties of the cerebrospinal fluid (CSF) and latex-based antigen detection assays, makes this illness a narrowly defined entity. Therefore, we chose this infectious disease to study the value of a PCR assay with two sets of primers as a diagnostic method. One primer set was selected from the nucleotide sequence encoding the outer-membrane lipoprotein P6, present in both capsulate and noncapsulate $H$. influenzae strains examined ${ }^{10,11}$ and would be expected to react with all $H$. influenzae strains. The second primer set was selected from sequences within the gene encoding the capsulation-associated Bex A protein, ${ }^{12}$ a protein most probably involved in the intracellular transportation of the capsular polysaccharide, and would be expected to react only with capsulate $H$. influenzae strains.

The specificity of our primer sets for different species and types of Haemophilus and the sensitivity of the assay on isolated DNA and bacterial cells are described. We further report the results of the PCR assay as a diagnostic tool on 200 consecutive samples of CSF from patients with meningitis. 


\section{Materials and methods}

\section{Bacterial strains and CSF samples}

Strains and CSF samples were submitted by bacteriologists throughout the Netherlands to the Netherlands Reference Laboratory for Bacterial Meningitis, which identified and serotyped the strains. Reference strains of $H$. influenzae (various subtypes) were obtained from $\mathrm{Dr}$ D. M. Granoff and have been described previously. ${ }^{13}$ The strains used are listed in table I.

Two hundred samples of CSF from patients suffering from meningitis were tested consecutively by PCR with a strict set of protocols, essentially as described by Kwok and Higuchi. ${ }^{9}$ Most CSF samples tested by PCR were supernates obtained after centrifugation of the clinical samples and, generally, no data were available on the numbers of bacteria cultured from the samples.

\section{Preparation of DNA}

For bacterial strains, DNA was extracted from overnight cultures as described earlier. ${ }^{14}$ For staphylococci an additional incubation with lysostaphin (Sigma) $250 \mu \mathrm{g} / \mathrm{ml}$ was included; for streptococci a treatment with mutanolysin (Sigma) $20 \mu \mathrm{g} / \mathrm{ml}$ was added. DNA was liberated from CSF by incubating the specimen for $10 \mathrm{~min}$ at $95^{\circ} \mathrm{C}$ followed by centrifugation $(10000 \mathrm{~g}$ for $1 \mathrm{~min}$ ) and placing the tubes on wet ice. A $25-\mu$ l volume of each cerebrospinal fluid supernate was used for the PCR assay. The sensitivity of this procedure was

Table I. Results of PCR DNA amplification of Haemophilus spp. and other bacteria by two primer sets

\begin{tabular}{|c|c|c|c|}
\hline \multirow[b]{2}{*}{ Strain } & \multirow{2}{*}{$\begin{array}{l}\text { Number } \\
\text { tested }\end{array}$} & \multicolumn{2}{|c|}{$\begin{array}{c}\text { Reaction with primer } \\
\text { set* }^{*}\end{array}$} \\
\hline & & $1(\operatorname{BexA})$ & 2 (P6) \\
\hline H. influenzae serotype $b$ & 10 & + & + \\
\hline H. influenzae serotype a & 1 & + & + \\
\hline H. influenzae serotype c & $i$ & + & + \\
\hline H. influenzae serotype d & 1 & + & + \\
\hline H. influenzae serotype e & 1 & + & + \\
\hline H. influenzae serotype f & 1 & + & + \\
\hline H. influenzae non-typable & 10 & - & + \\
\hline H. parainfluenzae & 7 & - & - \\
\hline H. parainfluenzae & 2 & - & + \\
\hline H. aphrophilus & 3 & - & - \\
\hline H. paraphrophilus & 3 & - & - \\
\hline H. segnis & 1 & - & - \\
\hline H. haemolyticus & 3 & - & + \\
\hline H. aegyptius & 3 & - & + \\
\hline
\end{tabular}

${ }^{*} E$. coli (2 strains), S. aureus (1), N. meningitidis serogroups A,B,C (3), Str. pneumoniae (2), Str. agalactiae (3), S. typhimurium (2), L. monocytogenes (2), and S. epidermidis (2) and 10 other genera of bacteria, not commonly involved in meningitis, gave negative reactions with both primer sets. compared with the method described by Boom et al. ${ }^{15}$ In experiments with serial dilutions of $H$. influenzae cells the same heating technique was used.

\section{Oligonucleotide primers}

Primer set 1 was derived from the published sequence for the Bex A protein, a capsulation-associated protein. ${ }^{12}$ Oligonucleotides were selected from this sequence by excluding homologous sequences of similar proteins of Escherichia coli and Salmonella typhimurium. ${ }^{12}$ The amplified region contains the nucleotide numbers +277 to +619 of the protein-coding nucleic-acid sequence, which results in a length of the amplified product of 343 base-pairs. The oligonucleotides for primer set 1 were:

\section{HI-I : 5'-CGTTTGTATGATGTTGATCCAGACT-3' HI-II: 5'-TGTCCATGTCTTCAAAATGATG-3' \\ HI-III (probe; nucleotide numbers +445 to +475 ): 5'-GTGATTGCAGTAGGGGATTCGCGC- TTTGCAG-3'}

Primer set 2 was derived from the published sequence for the outer-membrane protein P6 of $\mathrm{H}$. influenzae. ${ }^{10}$ Oligonucleotides were selected from these sequences by excluding homologous sequences of a similar protein in E. coli. ${ }^{16}$ The amplified region contains the nucleotides +103 to +375 of the protein-encoding nucleic-acid sequence, making the length of the amplified products 273 base-pairs. The oligonucleotides for primer set 2 were:

\section{HI-IV : 5'-ACTTTTGGCGGTTACTCTGT-3' \\ HI-V: 5'-TGTGCCTAATTTACCAGCAT-3' \\ HI-VI (probe; nucleotide numbers +217 to +243 ): 5'-GCATATTTAAATGCAACACCA- GCTGCT-3'}

The oligonucleotides were custom synthesised by Eurosequence (Groningen, The Netherlands) in an Applied Biosystems DNA Synthesizer 380 B.

\section{Amplification and detection of $H$. influenzae $D N A$}

The amplification procedure with both primer sets was based on the description by Saiki et al. ${ }^{1}$ and performed in a final volume of $100 \mu$ l. The reaction mixture contained $10 \mathrm{~mm}$ Tris-hydrochloride (pH 8.3), $50 \mathrm{mM} \mathrm{KCl}, 2 \mathrm{mM}$ $\mathrm{MgCl}_{2}$, gelatin $0.001 \%, 200 \mu \mathrm{M}$ each of the deoxyribonucleotides, approximately $0.35 \mu \mathrm{M}$ each of the oligonucleotides, Taq polymerase (Perkin-Elmer Cetus) 2.5 units, to which were added samples containing isolated $H$. influenzae DNA $10 \mathrm{ng}$, isolated DNA of other bacteria $50 \mathrm{ng}$, or $25 \mu \mathrm{l}$ of CSF. The mixtures were processed in a programmable DNA thermal cycler (Perkin-Elmer Cetus) and subjected to 35 or 40 , if indicated, cycles of amplification. One cycle consisted of $1 \mathrm{~min}$ at $95^{\circ} \mathrm{C}$, $1 \mathrm{~min}$ at $55^{\circ} \mathrm{C}$ and $2 \mathrm{~min}$ at $72^{\circ} \mathrm{C}$. After the final cycle, the tubes were incubated for a further $8 \mathrm{~min}$ at $72^{\circ} \mathrm{C}$. Electrophoresis was carried out on $10 \mu \mathrm{l}$ of amplified sample in agarose $2 \%$ gels with a 123 -bp DNA ladder 
(BRL, Bethesda Research Laboratory) as a mol.-wt marker. DNA was transferred on to nylon filters (Zetaprobe; Bio-Rad) under alkaline conditions (0.4 N $\mathrm{NaOH}$ ). Hybridisation was done at $55^{\circ} \mathrm{C}$ overnight in $6 \times \mathrm{SSC}(1 \times \mathrm{SSC}$ is $0.15 \mathrm{M} \mathrm{NaCl}$ and $0.015 \mathrm{M}$ sodiumcitrate), sodium dodecyl sulphate (SDS) $0.5 \%$, Ficollpolyvinylpyrrolidone-BSA $0 \cdot 1 \% \quad(5 \times$ Denhardts solution), $100 \mu \mathrm{g} / \mathrm{ml}$ of sheared, denatured salmon sperm DNA and ${ }^{32} \mathrm{P}-5^{\prime}$-labelled probe oligonucleotides HI-III for primer set 1 and HI-VI for primer set 2 . After hybridisation, the blots were washed twice with $2 \times$ SSC and SDS $0.1 \%$ at room temperature for $10 \mathrm{~min}$ and twice with $2 \times \mathrm{SSC}$ and SDS $0.5 \%$ at $55^{\circ} \mathrm{C}$ for $30 \mathrm{~min}$. Membranes were finally exposed to radiographic films for $16 \mathrm{~h}$ in cassettes.

\section{Results}

\section{Specificity of PCR with the two primer sets}

The results of experiments performed to analyse the specificity of primer sets 1 and 2 for Haemophilus spp. are listed in table I. Primer set 1 , which amplifies a sequence within the gene encoding the capsulation-associated Bex A protein reacted with capsulate $H$. influenzae strains (serotypes a-f). Primer set 2 (outer-membrane protein P6 derived) reacted with both capsulate and non-capsulate strains of $H$. influenzae and with strains of $H$. haemolyticus and $H$. aegyptius, which are closely related to $H$. influenzae. ${ }^{17}$ Two of the nine strains of $H$. parainfluenzae examined also reacted with primer set 2 and hybridised with probe HI-VI. All other genera of bacteria examined gave negative reactions with both primer sets (table I).

Human (placenta) DNA did not react with primer set 1 , but amplification with primer set 2 resulted in three faintly visible bands of incorrect sizes, that did not hybridise with probe HI-VI.

The reaction of both primer sets with different types of $H$. influenzae is shown in fig. 1. Lower signal intensities were noticed with primer set 1 for some serotypes other than serotype b and for the $H$. influenzae serotype b strain $17 \mathrm{H}$, presented in lane 4. This $H$. influenzae b subtype $17 \mathrm{H}$ strain is known to belong to division II of $H$. influenzae, ${ }^{18}$ a small cluster of $H$. influenzae strains distantly related to the much more common division I strains. The lower signal intensities were attributed to the imperfect matching of the oligonucleotides to their target DNA.

\section{Sensitivity of PCR with the two primers}

The sensitivities of the PCR with both primer sets were investigated with serial dilutions of

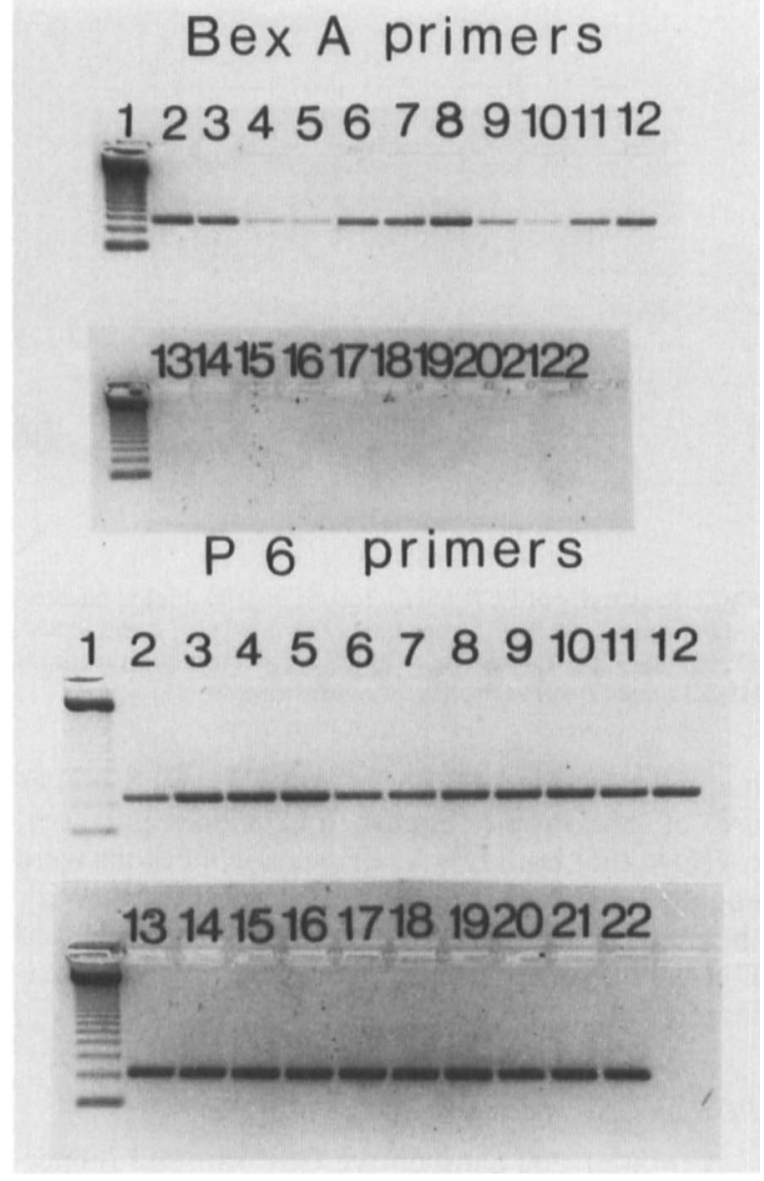

Fig. 1. PCR DNA amplication of strains of $H$. influenzae (10 ng DNA) with primer set 1 (Bex A) (upper panel) and primer set 2 (P6) (lower panel). Lane 1: 123 bp DNA ladder (mol. wt marker); $2: H$. influenzae type b Minna ST $1 \mathrm{H} ; 3: H$. influenzae type b 649 ST 1L; 4: $H$. influenzae type b Rab ST 17H; 5: $H$. influenzae type a (ref); 6: $H$. influenzae type b (ref); 7: $H$. influenzae type c (ref); 8:H. influenzae type d (ref); $9: H$. influenzae type e (ref); $10: H$. influenzae type $\mathrm{f}(\mathrm{ref}) ; 11$ and 12 : $H$. influenzae type b (Netherlands isolates); 13-22:H. influenzae non-typable (Netherlands isolates).

isolated DNA and with bacterial cells of an $H$. influenzae serotype b strain with 40 amplification cycles. Serial dilutions of DNA gave, reproducibly, a lower limit of detection of $0.05 \mathrm{pg}$ for primer set 1 and $0.01 \mathrm{pg}$ for primer set 2 . The lowest numbers of bacterial cells detected, as determined by serial dilution, plating of samples on agar and counting of colonies, were, respectively, $50 \mathrm{cfu}$ for primer set 1 and $5 \mathrm{cfu}$ for primer set 2 (fig. 2). On visual inspection, Southern blot analysis did not appreciably increase sensitivity compared with agarose gel electrophoresis for both primer sets (fig. 2). Comparison of the heating technique used with the 


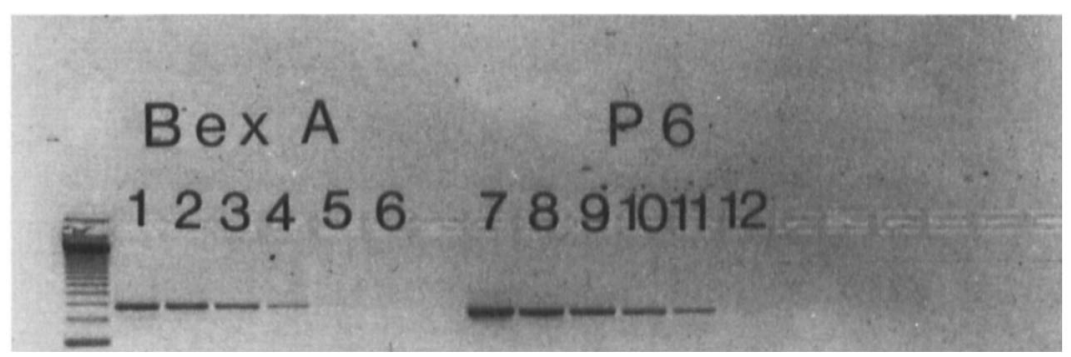

Fig. 2. Sensitivity of PCR (40 cycles) on serially diluted bacterial cells of $H$. influenzae type b (ref). Lanes 1-6: primer set 1 (Bex A); 7-12: primer set 2 (P6). Lanes 1 and 7:5 $510^{4} \mathrm{cfu} ; 2$ and $8: 5 \times 10^{3} \mathrm{cfu} ; 3$ and $9: 5 \times 10^{2} \mathrm{cfu} ; 4$ and $10: 50 \mathrm{cfu} ; 5$ and $11: 5 \mathrm{cfu} ; 6$ and 12: $0.5 \mathrm{cfu}$. Upper panel: agarose gel $2 \%$ electrophoretic analysis. Lower panel: Southern blot analysis with HI-III (lanes $1-6)$ and HI-VI (lanes 7-12) as probes for hybridisation.

method described by Boom et al., ${ }^{15}$ which makes use of chaotropic agents and silica particles, revealed that both DNA purification methods were equally sensitive in our tests (data not shown). With the method described by Boom et al. ${ }^{15}$ the yield of DNA recovered after purification was approximately $50 \%{ }^{15}$

\section{PCR on CSF specimens}

A total of 200 consecutive CSF samples (generally supernates) were tested by PCR with both primer sets. The culture results of these samples are listed in table II. Initially, 40 cycles of amplification were used. This resulted in $5 \%$ positive PCR signals with one or both primer sets in CSF samples from which bacteria other than $H$. influenzae or no bacteria were cultured. Those CSF samples gave

Table II. Culture results of 200 consecutive CSF samples from patients suffering from meningitis

\begin{tabular}{lc}
\hline Bacterial species & $\begin{array}{c}\text { Number } \\
\text { of isolates }\end{array}$ \\
\hline H. influenzae & 40 \\
N. meningitidis & 47 \\
Str. pneumoniae & 16 \\
Str. agalactiae & 3 \\
L. monocytogenes & 1 \\
S. aureus & 3 \\
S. epidermidis & 4 \\
Other species & 16 \\
Culture negative & 70 \\
Total & 200 \\
\hline
\end{tabular}

faint, hardly visible bands of correct sizes that hybridised with the probes. The difference in band intensities between truly and most likely PCR falsepositive CSF samples after 40 cycles of amplification is shown in fig. 3.

From these results and the data from $\mathrm{Kwok}^{9}$ we assumed that the false-positive reactions were due to contamination. Therefore, after 50 consecutive samples, the protocol for the following 150 samples was switched to 35 cycles of amplification, which resulted in some reduction of band intensity in $H$. influenzae culture-positive samples but also in the complete disappearance of signals in other CSF samples. All CSF samples that were positive for Neisseria meningitidis, Streptococcus pneumoniae, Str. agalactiae, Listeria monocytogenes, Staphylococcus aureus, $S$. epidermidis and other genera of bacteria on culture and those with negative culture results gave negative results in the PCR test with both primer sets. From the $40 \mathrm{CSF}$ samples that

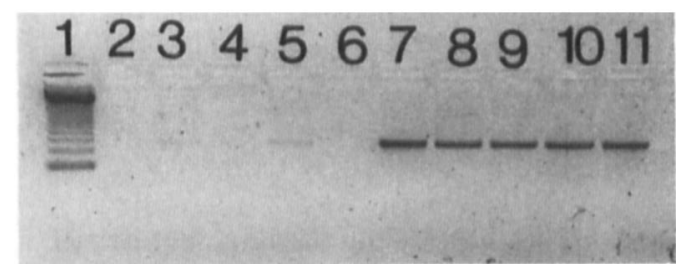

Fig. 3. PCR ( 40 cycles) DNA amplification of 10 CSF samples with primer set 1 (Bex A). Lane 1: 123 bp DNA ladder (mol. wt marker); 2-11: amplified CSF. The culture results of these samples were: lane $2: N$. meningitidis; $3: N$. meningitidis; $4: E$. coli; 5: Str. pneumoniae; 6: $N$. meningitidis; 7-11: $H$. influenzae type $b$. 
were culture-positive for $\boldsymbol{H}$. influenzae, serotype b was isolated from 38 and non-typable strains from two. Thirty-nine of the CSF samples that were culture-positive for $H$. influenzae were PCR positive; 37 gave positive results with both primer sets and two, the samples from which non-typable $H$. influenzae strains were isolated, were positive only with primer set 2 . From the PCR-negative, culturepositive sample, only a single colony of $H$. influenzae type b was grown. On the other hand, some of the other CSF samples were known to be also culturepositive but with only a few colonies of $H$. influenzae, yet were, nevertheless, PCR-positive, producing clearly visible bands of correct sizes on agarose gels with both primer sets.

\section{Discussion}

PCR DNA amplification is a technology that can be adapted easily to identify micro-organisms involved in infectious diseases. The exquisite specificity and sensitivity make the technique very attractive as a diagnostic method. Unfortunately, it is reported to be very susceptible to contamination in most laboratories. ${ }^{9}$ We also were confronted with contamination, leading, after 40 amplification cycles, to amplified DNA of the correct size that hybridised with our probes in $5 \%$ of $\mathrm{H}$. influenzae culture-negative samples. By reducing the number of cycles to 35 and strengthening adherence to a strict set of protocols, problems caused by contamination in the CSF samples were subsequently avoided.

Studies on isolated DNA and bacterial cells, both revealed a reproducible sensitivity of about 10-50 $H$. influenzae cells (or its DNA equivalent), primer set 1 consistently being somewhat less sensitive than primer set 2 . These sensitivities were achieved with agarose gel $2 \%$ electrophoresis and were not increased appreciably by Southern blot analysis with the ${ }^{32} \mathrm{P}$-labelled probes $\mathrm{HI}-\mathrm{III}$ and $\mathrm{HI}-\mathrm{VI}$. Slot blot or dot blot analysis may increase the sensitivity as has been described, e.g., for $L$. pneumophila. $^{5}$

The two primer sets used in PCR for the detection of $H$. influenzae had different specificities. Primer set 1 was derived from a capsulation-associated gene $^{12}$ and reacted with $H$. influenzae serotype b strains and with all other serotypes, although to a variable extent, but not with non-capsulate $H$. influenzae strains (table I). This was not unexpected as genes, similar to the Bex A gene of serotype $b$, have been described in the other serotypes of $H$. influenzae. ${ }^{12}$ Primer set 2 , derived from the gene for outer-membrane lipoprotein $\mathrm{P} 6,{ }^{10,11}$ reacted with all $H$. influenzae strains and also with such closely related species as $H$. haemolyticus and $H$. aegyptius. This is in agreement with previous results obtained with monoclonal antibodies, showing that these three species have the same outer-membrane protein P6 epitope. ${ }^{19}$ Somewhat unexpected was the reaction of this primer set with two of the nine $H$. parainfluenzae strains, but it was known that the same monoclonal antibodies also react with a minority of $H$. parainfluenzae strains. ${ }^{19}$ This probably indicates that some strains of $H$. parainfluenzae have a protein related to the lipoprotein P6 of $H$. influenzae.

PCR DNA amplification showed a sensitivity for the detection of $H$. influenzae in CSF from patients with bacterial meningitis similar to culture. This sensitivity was superior to that of antigen detection in CSF by immuno-electrophoresis or latex-agglutination: ${ }^{20}$ the two CSF samples with noncapsulated $H$. influenzae strains and nine of the $38 \mathrm{H}$. influenzae serotype b culture-positive CSF samples gave negative reactions in these antigen detection tests. For PCR, mostly supernates from CSF were used, whereas sediments were used for culture. In the few samples for which cerebrospinal fluids in toto, were used for both techniques, PCR was positive even in the presence of only a few cfu as determined by culture. Furthermore, PCR was positive with two CSF samples from patients with $H$. influenzae meningitis who had been treated for several days with antibiotics and for which culture results had become negative (data not shown).

We conclude that the PCR DNA amplification is equivalent to culture in respect of the sensitivity of detection of $H$. influenzae in CSF. It appears to be a matter of preference and secondary benefits (e.g., antibiotic sensitivity tests) whether to choose to detect $H$. influenzae in this infectious disease by culture or PCR DNA amplification. Moreover the PCR method is valuable for identification of $H$. influenzae if cultures are negative because of antibiotic treatment before sampling; the two different primer sets make distinction between capsulate and noncapsulate $H$. influenzae possible. 


\section{REFERENCES}

1. Saiki RK, Gelfand DH, Stoffel S et al. Primer-detected enzymatic amplification of DNA with a thermostable DNA polymerase. Science $1988 ; 239: 487-491$.

2. Ou C-Y, Kwok S, Mitchell SW et al. DNA amplification for direct detection of HIV-1 in DNA of peripheral blood mononuclear cells. Science 1987; 239: 295-297.

3. Morris BJ, Flanagan JL, McKinnon KJ, Nightingale BN. Papillomavirus screening of cervical lavages by polymerase chain reaction. Lancet 1988; 2: 1368.

4. Demmler GJ, Buffone GJ, Schimbor CM, May RA. Detection of cytomegalovirus in urine from newborns by using polymerase chain reaction DNA amplification. $J$ Infect Dis 1988; 158 : 1177-1184.

5. Starnbach MN, Falkow S, Tompkins LS. Species-specific detection of Legionella pneumophila in water by DNA amplification and hybridization. J Clin Microbiol 1989; 27: $1257-1261$.

6. van Eys GJJM, Gravekamp C, Gerritsen MJ et al. Detection of leptospires in urine by polymerase chain reaction. $J$ Clin Microbiol 1989; 27 : 2258-2262.

7. Brisson-Noël A, Gicquel B, Lecossier D, Lévy-Frébault V, Nassif X, Hance AJ. Rapid diagnosis of tuberculosis by amplification of mycobacterial DNA in clinical samples. Lancet 1989; 2: 1069-1071.

8. Burg JL, Grover CM, Pouletty P, Boothroyd JC. Direct and sensitive detection of a pathogenic protozoan, Toxoplasma gondii, by polymerase chain reaction. $J$ Clin Microbiol 1989; 27: 1787-1792.

9. Kwok S, Higuchi R. Avoiding false positives with PCR. Nature $1989 ; 339$ : 237-238.

10. Deich RA, Metcalf BJ, Finn CW, Farley JE, Green BA. Cloning of genes encoding a 15000 -dalton peptidoglycan-associated outer membrane lipoprotein and an antigenically related 15000 -dalton protein from Haemophilus influenzae. J Bacteriol 1988; 170: 489-498.
11. Nelson MB, Apicella MA, Murphy TF, VanKeulen $H$, Spotila LD, Rekosh D. Cloning and sequencing of Haemophilus influenzae outer membrane protein P6. Infect Immun 1988; 56: 128-134.

12. Kroll JS, Hopkins I, Moxon ER. Capsule loss in $H$. influenzae type $\mathrm{b}$ occurs by recombination-mediated disruption of a gene essential for polysaccharide export. Cell 1988; 53: 347-356.

13. Barenkamp SJ, Munson RS, Granoff DM. Comparison of outer-membrane protein subtypes and biotypes of isolates of Haemophilus influenzae type b. J Infect Dis $1981 ; 144: 480$.

14. van Ketel RJ, ter Schegget J, Zanen HC. Molecular epidemiology of Legionella pneumophila serogroup 1. J Clin Microbiol 1984; 20: 362-364.

15. Boom R, Sol CJA, Salimans MMM, Jansen CL, Wertheimvan Dillen PME, van der Noordaa J. Rapid and simple method for purification of nucleic acids. J Clin Microbiol $1990 ; 28: 495-503$

16. Chen R, Henning U. Nucleotide sequence of the gene for the peptidoglycan-associated lipoprotein of Escherichia coli K12. Eur J Biochem 1987; 163: 73-77.

17. Kilian M. A taxonomic study of the genus Haemophilus, with the proposal of a new species. $J$ Gen Microbiol $1976 ; 93: 9-62$.

18. Musser JM, Kroll JS, Moxon ER, Selander RK. Clonal population structure of encapsulated Haemophilus influenzae. Infect Immun 1988; 56: 1837-1845.

19. Groeneveld K, van Alphen L, van Ketel RJ, Geelen-van den Broek L, Eijk PP, Zanen HC. Nonculture detection of Haemophilus influenzae in sputum with monoclonal antibodies specific for outer membrane lipoprotein P6. J Clin Microbiol 1989; 27: 2263-2267.

20. Netherlands Reference Laboratory for Bacterial Meningitis. Bacterial meningitis in the Netherlands. Annual report. 1988, University of Amsterdam, Amsterdam, The Netherlands. 